\title{
Effects of pre-injection strategy on combustion performance of methanol/diesel dual fuel engine at low load
}

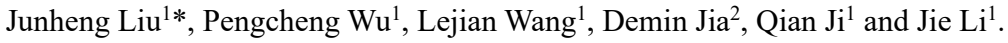 \\ ${ }^{1}$ School of Automotive and Traffic Engineering, Jiangsu University, Zhenjiang Jiangsu, 212013, China \\ ${ }^{2}$ Science Research Institute, Weichai Power Co., Ltd, Weifang 261061, China
}

\begin{abstract}
In this paper, the effect of pre-injection timing on the combustion and emission performance of methanol/diesel high premixed charge compression ignition (HPCCI) combustion mode at low load was studied by three-dimensional numerical simulation. The simulation is carried out under the conditions of 1900 $\mathrm{r} / \mathrm{min}$ and $25 \%$ load, and the pre-injection diesel mass remains constant and the pre-injection timing is changed under the conditions of $50 \%$ and $60 \%$ methanol ratio respectively. The results show that with the delay of preinjection timing, the evaporation of pre-injected fuel in cylinder becomes faster, the low temperature reaction is enhanced, and the peak value of heat release rate is higher. In addition, the distribution of pre-injected diesel in cylinder and the position of impact wall are the important factors affecting the combustion and emission performance in cylinder, and when the injection timing is $-35{ }^{\circ} \mathrm{CA}$ ATDC, the combustion and emission characteristics of the engine are optimal. Finally, by comparing with the traditional RCCI combustion mode, the enhancement ability of HPCCI combustion mode on methanol combustion efficiency under low load is verified and analyzed.
\end{abstract}

\section{Introduction}

In view of the shortcomings of traditional diesel engines, in order to achieve high-efficiency and low-temperature controllable combustion of internal combustion engines, Reitz et al. [1] proposed a dual-fuel reactivity controlled compression ignition (RCCI) combustion concept, which uses direct injection of high cetane number fuel to ignite high-octane fuel injected into the port.

However, due to methanol fuel's properties including the high latent heat of vaporization, easy formation of homogeneous mixture and fast combustion speed, the RCCI strategy still has the problems of poor emission at low load and rough combustion at high load in some working conditions [2]. The results show that the addition of high proportion of methanol can reduce NOx, $\mathrm{NO}$ and soot emissions, but $\mathrm{NO}_{2}, \mathrm{CO}$, THC, formaldehyde and unburned methanol emissions increase [3]. Due to the low combustion temperature at low load, $\mathrm{HC}$ and $\mathrm{CO}$ emissions increase [4-5]. Therefore, in view of the existing problems of the current RCCI combustion mode, it is necessary to further study the optimization strategy of the methanol/diesel dual-fuel RCCI combustion mode.

The basic idea of high premixed charge compression ignition (HPCCI) strategy is to form a low-reactivity fuel premixed gas by port injection, and then form a lean homogeneous premixed gas with improved reactivity through earlier large-proportion pre-injection of direct injection fuel, afterwards the pre-mixed gas is ignited by the highly reactivity fuel injected near the top dead center.
Due to the double injection strategy of direct injection fuel, through the adjustment of pre-injection proportion and pre-injection/main-injection timing, the ideal in-cylinder equivalence ratio and reactivity distribution can be achieved more flexibly under different operating conditions, and the ignition time and combustion process can be effectively controlled.

In this paper, a 6-cylinder heavy-duty methanol/diesel dual fuel engine was taken as the research object, and simulation analysis was conducted based on CONVERGE software to explore the influence of pre-injection strategy in combustion efficiency and comprehensive emission performance of methanol/diesel dual fuel engine with HPCCI strategy at low load.

\section{Simulation method}

\subsection{Model establish}

The detailed parameters of the simulated diesel engine are shown in Table 1. In the dual fuel RCCI experiment, methanol is supplied by an independent low-pressure injection system installed on the intake manifold of the engine, while diesel is injected into the cylinder through the original high-pressure common rail direct injection system. In order to accurately control the intake ratio in the experiment, the original engine intake supercharger was removed and an additional compressor was used to provide constant pressure intake air.

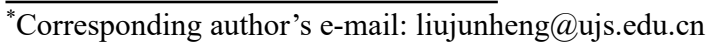


Table 1. Specifications of test engine.

\begin{tabular}{ll}
\hline Item & Specification \\
\hline Engine type & $\begin{array}{l}\text { In line, } 6 \text { cylinders, } \\
\text { common rail }\end{array}$ \\
Bore $\times$ stroke $(\mathrm{mm})$ & $127 \times 165$ \\
$\begin{array}{l}\text { Displacement }(\mathrm{L}) \\
\text { Compression ratio }\end{array}$ & 12.54 \\
$\begin{array}{l}\text { Nozzle number } \\
\text { Hole diameter }(\mathrm{mm})\end{array}$ & 8 \\
Angle of nozzle $\left({ }^{\circ}\right)$ & 0.219 \\
$\begin{array}{l}\text { Maximum power speed } \\
(\mathrm{r} / \text { min })\end{array}$ & 146 \\
$\begin{array}{l}\text { Maximum torque speed } \\
(\mathrm{r} / \text { min })\end{array}$ & 1900 \\
\hline
\end{tabular}

According to the geometric parameters and related technical parameters of the test engine, the 3D simulation model is established, as shown in figure 1. Because of the adaptive grid of CONVERGE software, the computing grid can be encrypted in time and space, which can improve the calculation accuracy and save the calculation time. Therefore, the basic calculation grid size of the model is $0.4 \mathrm{~mm}$, and the key areas of the model are properly encrypted. The speed, temperature and fuel species are set with adaptive grid encryption, which takes the calculation accuracy and calculation time into account.

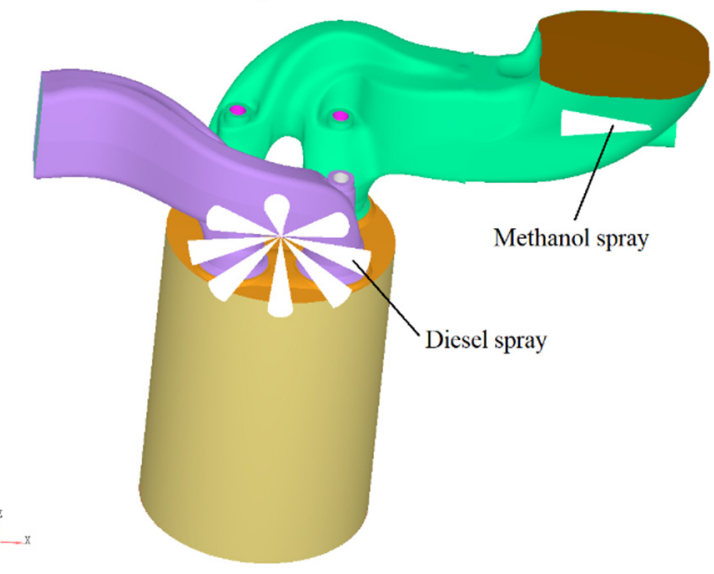

Figure 1. 3D calculation model of methanol/diesel dual fuel engine.

\subsection{Selection of calculation models}

In this paper, n-heptane $\left(\mathrm{C}_{7} \mathrm{H}_{16}\right)$ is used as the reference fuel for in-cylinder combustion reaction calculation. The main models used in the calculation are shown in Table 2.

Table 2. Calculation models.

\begin{tabular}{ll}
\hline Combustion model & SAGE detailed chemistry \\
\hline Turbulence model & RNG k- $\varepsilon$ \\
Breakup model & KH-RT \\
Evaporation model & Frossling \\
Collision model & NTC-collision \\
Wall interaction model & Wall Film \\
Wall heat transfer model & O'Rourke and Amsden \\
NOx model & Extended Zeldovich \\
Soot model & Hiroyasu \\
\hline
\end{tabular}

\subsection{Research program}

This paper mainly studies the effect of pre-injection strategy on the combustion and emission performance of methanol/diesel dual-fuel engines using HPCCI combustion strategy, with emphasis on the improvement of poor combustion at low load. In this study, the circulating fuel injection mass is fixedly equivalent to $67.35 \mathrm{mg}$ diesel after energy value conversion, which corresponds to the $25 \%$ load condition of the original engine. In order to suppress the penetration capability of the pre-injected diesel and reduce the problem of droplets adhering to the wall; at the same time, to provide more intake air to achieve a higher EGR rate, a higher intake pressure is required [6]. Therefore, the inlet pressure is set to $0.3 \mathrm{MPa}$ in this study. Other boundary conditions are optimized values determined by previous research. Among them, the intake air temperature is fixed at $323 \mathrm{~K}$, the in-cylinder EGR rate is fixed at $30 \%$, and the maximum injection pressure is $220 \mathrm{MPa}$.

In order to comprehensively compare the effects of diesel pre-injection timing on the in-cylinder reaction process, combustion and emission performance under different methanol ratios, the diesel main-injection timing was fixed at $-4{ }^{\circ} \mathrm{CA}$ ATDC, and the simulation of changing the diesel pre-injection timing was carried out under $50 \%$ and $60 \%$ methanol ratio respectively. The injection mass of methanol was $70.492 \mathrm{mg}$ and $85.02 \mathrm{mg}$ respectively per circulation, and that of diesel was $34.675 \mathrm{mg}$ and 26.22 $\mathrm{mg}$, respectively. The pre-injection ratio of diesel fuel is $40 \%$ and $50 \%$ respectively to ensure that the quality of pre-injected diesel is approximately equal. In this paper, the crank angle uses a negative value to indicate before top dead center, and a positive value to indicate after top dead center.

\section{Results and analysis}

\subsection{Effects of pre-injection strategy on combustion performance}

Figure 2 (a) and (b) show the effects of pre-injection timing on cylinder pressure and heat release rate of methanol/diesel dual fuel engine at $50 \%$ and $60 \%$ methanol ratio respectively. The pre-injection timing changes from $-30{ }^{\circ} \mathrm{CA}$ to $-50{ }^{\circ} \mathrm{CA}$. It can be seen from the figure that the cylinder pressure and heat release rate show similar laws with the change of pre-injection timing under the two methanol ratios. Comparing the cylinder pressure and heat release rate curves at different pre-injection timings, it can be found that as the pre-injection timing advances, the low-temperature heat release in the cylinder is delayed and weakened, while the high-temperature heat release starts almost simultaneously under the control of the main-injection timing, and the exothermic peak is reached quickly. By comparing the heat release rate curves at different pre-injection timings, it can be seen that in the pre-injection timing range from $-30{ }^{\circ} \mathrm{CA}$ to $-50{ }^{\circ} \mathrm{CA}$, the early pre-injection combined with appropriate EGR rate can make the pre-injection high reactivity charge more effectively premixed in the cylinder, but the low 
temperature reaction intensity is effectively suppressed, so the heat release is still mainly concentrated in the main combustion stage [7]. At different pre-injection timing,

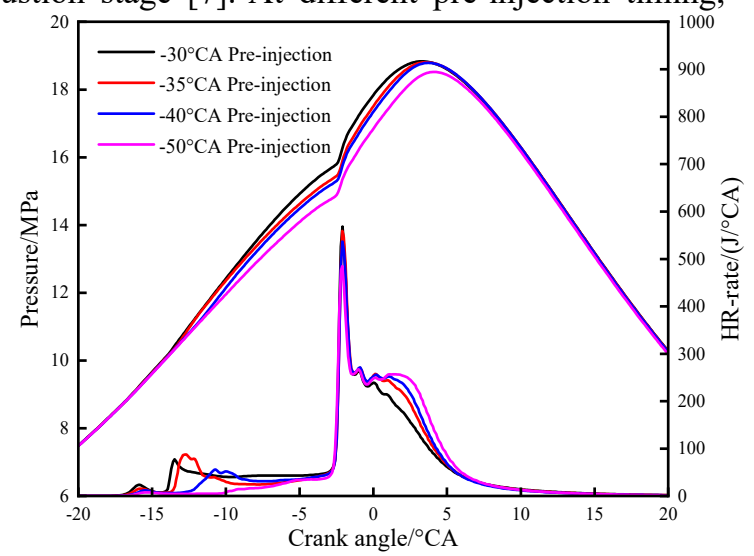

(a) $50 \%$ methanol ratio
HPCCI combustion mode can all effectively control the combustion start point and combustion phase.

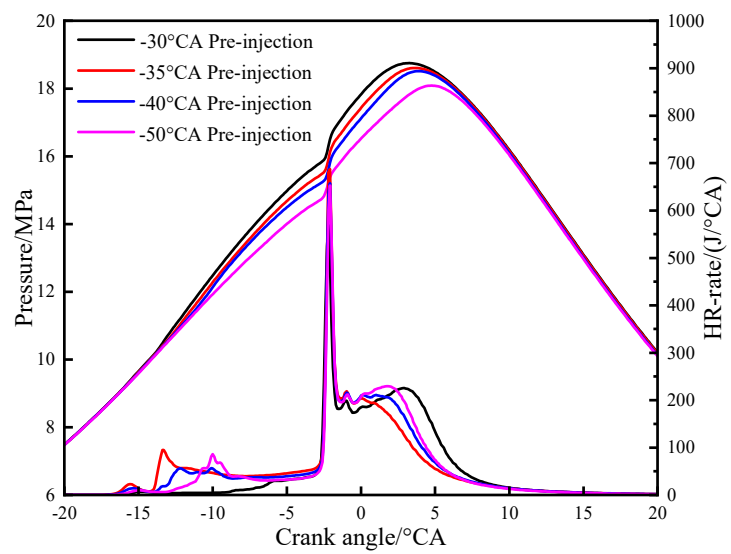

(b) $60 \%$ methanol ratio

Figure 2. Influence of pre-injection timing on cylinder pressure and heat release rate.

\subsection{Effects of pre-injection strategy on in-cylinder combustion efficiency and emissions}

Figure 3 shows the droplet distribution and wall impingement position corresponding to different preinjection timing. Although the intake inflow pressure is increased to $0.3 \mathrm{MPa}$ in this study, there are still different degrees of pre-injection wall adhesion at different preinjection timings.

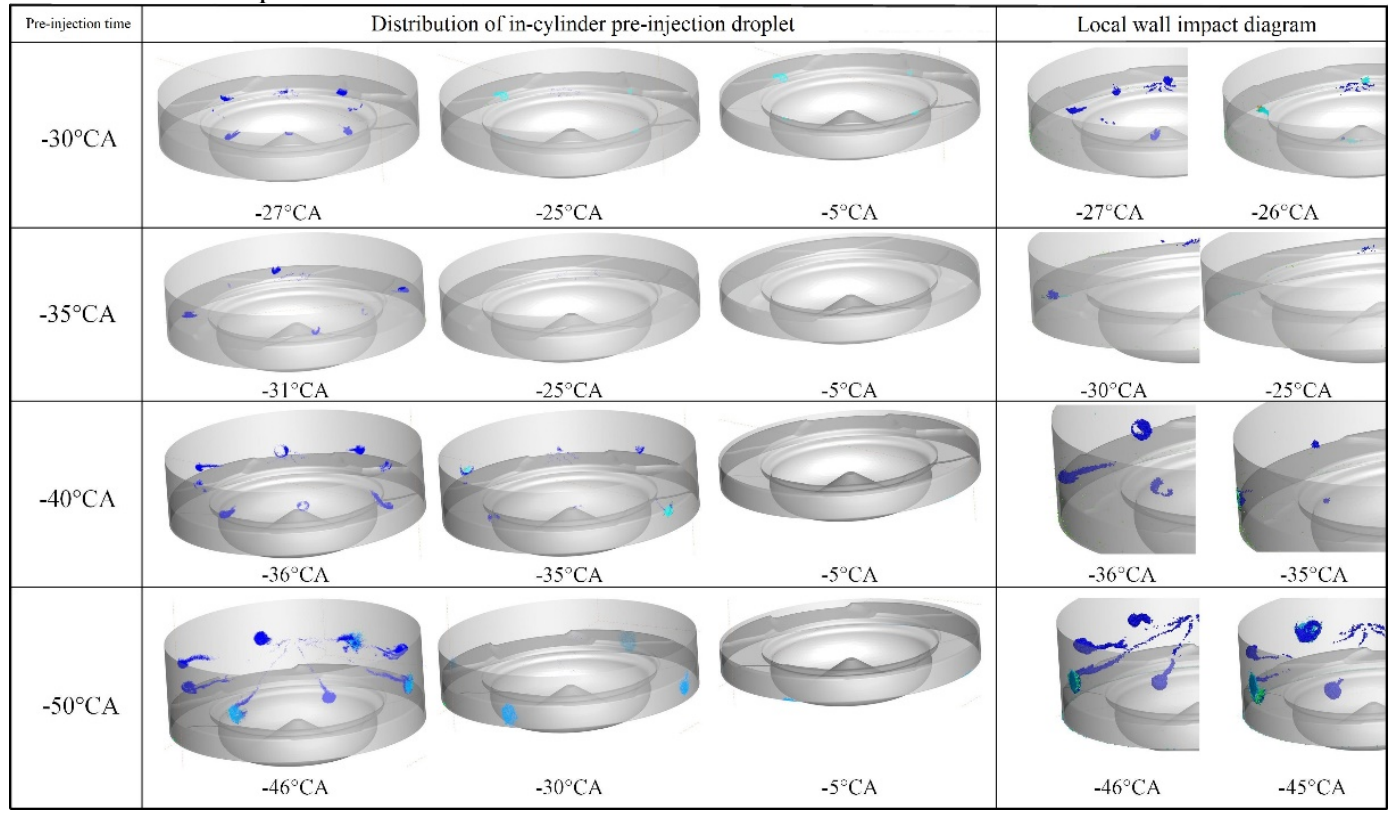

Figure 3. The influence of different pre-injection timing on the distribution of pre-injection droplets and wall impingement. (Blue represents the droplet without contact with the wall, light blue represents the attached droplet, and green represents the rebound droplet.)

It can be seen from the figure 3 that at the pre-injection timing of $-50{ }^{\circ} \mathrm{CA}$, due to the low pressure and temperature in the cylinder, the pre-injected diesel has a strong penetration ability, and the piston is far away from the TDC, so almost every fuel beam directly hits the wall. Some of the droplets bounce back and evaporate rapidly in the following crank angles, but a considerable part will adhere to the cylinder wall. Due to the cooling effect of the cylinder wall, the evaporation rate of these attached fuel is very slow. After that, as the piston moves up, the wall attached fuel enters the gap between the piston and the cylinder sleeve, thus cannot participate in the combustion reaction in the cylinder in time.

When the pre-injection timing is delayed to $-40{ }^{\circ} \mathrm{CA}$, although the impinging position of the fuel beam is still on the cylinder wall, the fuel evaporation is enhanced and the penetration ability is weakened due to the increase of the temperature and pressure in the cylinder. Therefore, only part of the fuel beam has wall attachment and the fuel quality on the wall is reduced. When the injection timing was further delayed to $-35^{\circ} \mathrm{CA}$, the fuel penetration ability is further weakened and the evaporation is further 
enhanced. However, due to the upward movement of the piston, the allowable injection distance of the fuel beam is shortened, and the impinging position of the pre-injection beam is on the top surface of the piston. Because the fuel impinges on the wall at a very large angle, the proportion of droplets rebounding is high, so the wall attached fuel mass is the least. At the time of $-30{ }^{\circ} \mathrm{CA}$ pre-injection, the allowable injection distance of the fuel beam is further shortened with the rising of the piston. The in-cylinder pre-injected diesel fuel is injected onto the step surface at the junction of the piston top surface and the piston bowl, and a certain amount of wall attachment is produced. From this time, if the fuel injection is further delayed, both the pre-injection diesel and the main-injection diesel will be injected into the combustion chamber bowl.

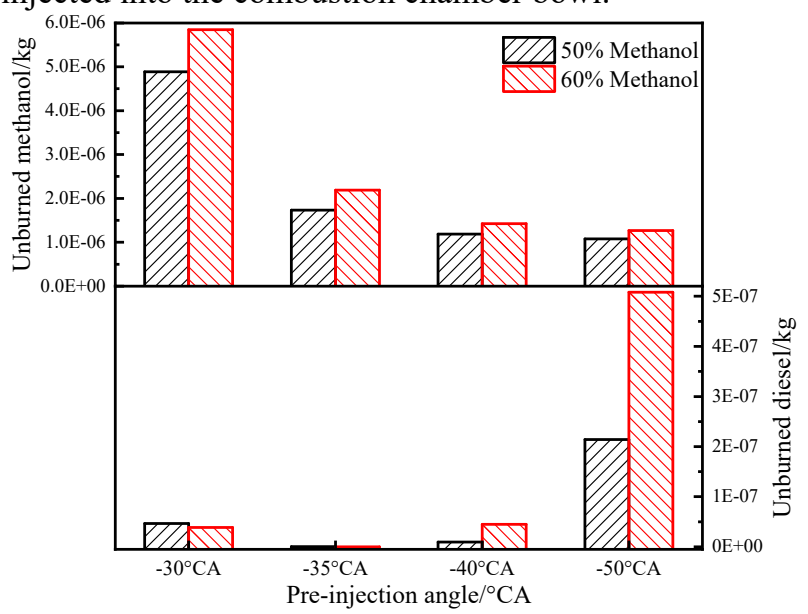

Figure 4. Effect of pre-injection timing on unburned fuel emissions.

Figure 4 shows the variation of unburned fuel emissions with pre-injection timing. The advance of preinjection timing can effectively reduce the unburned methanol emission, and the change of pre-injection timing from $-30{ }^{\circ} \mathrm{CA}$ to $-35{ }^{\circ} \mathrm{CA}$ results in a significant decrease of unburned methanol, and the value continues to decrease as pre-injection timing advances from $-35^{\circ} \mathrm{CA}$ to $-50{ }^{\circ} \mathrm{CA}$. According to Splitter et al. [8], the squish zone will not be mixed with direct injection diesel fuel either by single injection or by double injection if both injections are directed towards the bowl, moreover, the wall cooling in the squish zone is stronger and the combustion of lean mixture is further restrained, resulting in a lower percentage of complete combustion of fuel. When the first injection is directed toward the squish zone and the second toward the piston bowl, the premixed methanol can be oxidized more thoroughly in the whole combustion chamber space due to the split flow of direct injection diesel between the bowl and squish zone. The results show that the earlier the pre-injection, the better the diffusion of pre-injected diesel to the edge of squish zone, thus improving the combustion efficiency of methanol. After comparing the combustion and emission performance of different pre-injection timing, the pre-injection timing of $35^{\circ} \mathrm{CA}$ was selected as the optimal working condition.

\section{Conclusions}

In this paper, the effects of different pre-injection timing of DI Diesel on the in-cylinder reaction process, combustion and emission performance under methanol/diesel HPCCI combustion model were studied by three-dimensional CFD simulation. The main conclusions are as follows:

(1) The later the pre-injection timing is, the faster the pre-injection fuel evaporates in the cylinder, the stronger the low temperature reaction is, and the higher the peak heat release rate is, and the higher the in-cylinder pressure curve is.

(2) The different pre-injection timing results in the different in-cylinder distribution of pre-injection fuel and the attachment position. The attachment wall position corresponding to $-35{ }^{\circ} \mathrm{CA}$ pre-injection is on the top surface of the piston. At this time, the attached wall mass is the least, and the corresponding unburned diesel emission is close to zero. The earlier pre-injection is easy to produce the attachment on the cylinder wall, and the later $-30{ }^{\circ} \mathrm{CA}$ pre-injection produces more attached wall on the piston step surface. The pre-injection timing of $35^{\circ} \mathrm{CA}$ was determined as the optimal value by comparing the relationship between various emission values and preinjection timing.

(3) In the two injection strategy, the combination of the first pre-injection in the squish zone and the maininjection in the bowl can simultaneously improve the reactivity of the premixed gas in the bowl and the squish area, thus effectively promoting the combustion of premixed low reactivity methanol in the whole combustion chamber.

\section{Acknowledgments}

Authors wishing to acknowledge the project funded by China Postdoctoral Science Foundation (No. 2020M672133).

\section{References}

1. Kokjohn, S.L., Hanson, R.M., Splitter, D.A., Reitz, R.D. (2009) Experiments and modeling of dual-fuel HCCI and PCCI combustion using in-cylinder fuel blending. SAE Paper 2009-01-2647.

2. Duraisamy, G., Rangasamy, M., Govindan, N. (2020) A comparative study on methanol/diesel and methanol/PODE dual fuel RCCI combustion in an automotive diesel engine. Renew Energ, 145: 542556.

3. Wang, P., Yao, C.D., Han, G.P., Wei, H.Y. (2015) The impact of intake air temperature on performance and exhaust emissions of a diesel methanol dual fuel engine. Fuel, 162: 101-110.

4. Curran S, Hanson R, Wagner R, Reitz, R. (2013) Efficiency and emissions mapping of RCCI in a lightduty diesel engine. SAE Tech Paper 2013-01-0289.

5. Maurya, Kumar R. (2018) Characteristics and control of low temperature combustion engines. Springer. 
6. Li, Y.P., Jia, M., Xu, L.L., Bai, X.S. (2020) Multipleobjective optimization of methanol/diesel dual-fuel engine at low loads: A comparison of reactivity controlled compression ignition (RCCI) and direct dual fuel stratification (DDFS) strategies. Fuel, 262: 116673.

7. Liu, J.L., Shang, H.Y., Wang, H., Zheng, Z.Q., Wang, Q.P., Xue, Z.Z., Yao, M.F. (2017) Investigation on partially premixed combustion fueled with gasoline and PODE blends in a multi-cylinder heavy-duty diesel engine. Fuel, 193: 101-111.

8. Splitter, D., Hanson, R., Kokjohn, S., Wissink, M. (2011) Injection effects in low load RCCI dual-fuel combustion. SAE Paper 2011-24-0047. 